\title{
Forming groups of mobile learners that promote collaborative learning supported by mobile devices
}

\author{
Marie Hélène Wassa Mballo \\ PHD-student,University Cheikh Anta Diop, \\ Dakar,Senegal

Abstract. The educational system of today is marked by advances in information and communication technologies. Initially we attended computer-assisted learning, then mobile technology has in turn been integrated into the education system, hence the Mobile Learning. The technical capabilities of mobile devices associated with wireless technologies make them remote learning tools in their own right. Mobile Learning is a real potential for distance learning because it allows the learner to learn anywhere and at any time to ensure better collaboration between learners of mobile learning, gathered in small groups, hence the new concept of Mobile Computer Supported Collaborative Learning (MCSCL). One of MCSCL's problem is the learner groups' management. This problem is linked to the high mobility of learners (change of position, disconnection of the network, etc.). In our review of the literature we have made a classification of learner group training methods ensuring a better interaction while taking into account the mobility of the learners. In the context of disadvantaged areas, mobile phones can be used for learning.

Keywords: Mobile learning, Mobile Computer Supported Collaborative Learning.

\section{Introduction}

The socio-constructivist approach encourages learning through an interaction of the learner with his peers and the learner with his teacher. This approach is applied through different methods in the educational system, one of these methods is the collaborative learning method. 
Collaborative learning [1] [2] aims to improve the success of learners. It focuses on working in small groups in which learners of different abilities and talents strive to achieve a common goal.

With the proliferation of mobile devices (smart phones, tablets ...) and advances in mobile technology, collaborative online education tends to use mobile devices as a learning medium. This leads us to define a new concept that is collaborative learning supported by mobile devices "Mobile Computer Supported Collaborative Learning (MCSCL)" [3].

One of MCSCL's key issues is to train motivated and diligent groups of learners in their learning activities. In this paper we will focus on the formation of these groups of learners in the MCSCL.

\section{Learning group formation in collaborative learning}

The various studies carried out on collaborative learning in the classroom [4] [5] [6] [7] [8] [9] [10] [11] [12] [13] [14] [15] [16] [17] [18] [19] [18] [19] [20] [21] [22] [23] have a very positive record. Indeed, the learner develops attitudes that ensure better academic performance. Collaborative learning [24] suggests that learners are responsible and endowed with social skills. Indeed learners are responsible for their learning as well as that of the others.Collaborative learning is an approach that gives the learner a lot of freedom. The activities are not very directed and the learners manage the bulk of their group work. For example, the roles of learners are not assigned by the teacher in the case of collaborative learning, but learners negotiate these roles among themselves.

The MCSCL has a definite advantage for learners who are very mobile because of their professional occupation. Indeed, it ensures a strong collaboration and interaction between the learners, a greater autonomy of learning for the learner who has the possibility to come into contact with the other learners as well as the teacher anywhere and at any time.

The training of groups in distance learning platforms is done manually according to the objectives of the trainer. However, what about the number of learners who assiduously use these collaborative tools? Or learners who are not willing to use them? This proves to be a major problem in the implementation of collaborative distance learning if we really want to respond to the principles of collaborative learning, where the interdependence of learners is mandatory.

To promote collaborative distance learning, it will be necessary to:

- Train groups of learners whose numbers are small: to improve and facilitate the positive interdependence of learners. The collaborative approach recommends training small groups, ranging from 2 to 4 or 5 learners per team [7] [25]. Absolutely, a small number of learners promotes meaningful interactions while facilitating coordination and group management;

- Form groups of heterogeneous learners that facilitate positive interdependence, better learning outcomes and real interaction;

- Place a collaborative pedagogical strategy such as collective problem solving : 
- Establish a structuring or assistant technological system that aims to direct learners into their activities and learning. (i) Structuring systems provide an interface that guides learners in carrying out their collaborative activities. These systems structure activities and interaction situations. (ii) Assisting systems collect data from the interaction and analyze it to assist learners or trainers (supervisors).

The primary objective of working in a group is to promote the acquisition of social skills by learners, so the establishment of heterogeneous groups is the best approach [26]. Learner-formed groups, which are homogeneous, do not guarantee in the long run an environment conducive to collaborative learning [26] [27] [28] [29].

In practice, during this 21 st century coinciding with the advent of remote learning platforms, many researchers are attempting to offer learner group training solutions in Computer Assisted Collaborative Learning (CSCL). Thus, researchers are using mathematical models [30] [31] [32] [33] [34] [35], algorithms grouping learners [36] [37] [38] [39] [40] [41] [42] [43] [44], implement intelligent systems [45].

What we observe, however, in these works is that they focus more on static learners. This aspect of learner mobility should be taken into account. In terms of mobility, we refer to the apparatus used for learning, namely a mobile device.

Unlike the CSCL, mobile learning is best suited to collaborative learning because of the mobility that enhances the interactivity between the learners. So instead of having static groups, we will focus more on dynamic groups depending on the position of the learner. This brings us to the concept MCSCL.

\section{State of the art on the formation of groups of learners in MCSCL}

The MCSCL is a particularly dynamic environment. This environment must be able to adapt to changes in the learner's context and this, periodically (position, distance between learners, and availability of learning objects ...).

However, the MCSCL is generally exposed to a number of limitations such as: :

- Technical problems related to mobile technology: limited storage capacity, limited lifetime, frequent disconnection...

- Social problems: individualism, incomprehension...

- Geographical problems: climate change, displacement ...

These problems in the MCSCL impact the formation of groups. This means that it will be necessary to form dynamic groups taking into account these different aspects in order to ensure positive interdependence and to maintain the motivation and interaction of the learners.

Teams tend to propose mechanisms for group formation of learners in the MCSCL. Article [46] deals with a review of the literature on the problems of learners' group formation in the MCSCL. Indeed, the authors of this article provide research avenues to the MCSCL community in order to propose learner group training solutions. 
We find that some studies propose the formation of heterogeneous groups to promote interaction, others propose the creation of homogeneous groups. On the other hand, Messeguer and others [47], El-Bishouty and others[48], Tan, Kinshuk and Huang [49], Mujkanovic, Lowe and Willey [50], Muehlenbrock [50] focus on the learning environment to form groups. However, researchers recommend heterogeneous groups that promote collaborative learning through the interactions between learners and their motivation.

We have thus identified three essential criteria for the formation of learners'group, namely :

- The personal characteristics of the learners: This is about data that can help identify learners;

- Learning behavior: It is a matter of collecting data on the learner's behavior during the learning activity. These data can be: social interaction, participation in learning activities ...

- Contextual information: relates to real-time data provided from the learner's mobile device.

We find that the majority of the works use mainly the characteristics of the learner, to create groups of learners, these characteristics are: age, level of knowledge, experience ... To enrich the group of learners with the aim of having homogeneous or heterogeneous groups, tools to analyze the learner's behavior can be used, these tools can be digital portfolios, intelligent systems. An interesting aspect of mobile technology is the ability to have real-time information regardless of location and time, which is why the contextual information criterion is used for training groups of learners. In this work the most used information is the location of the learner who can be recovered through Wi-Fi tools, GPS ...

However on the twelve articles, only the authors Yin and others [51] combine the three criteria for the formation of groups with the establishment of homogeneous group. We believe that combining these three criteria allows for a generic learner group training system that can be adapted to any learning context.

Another aspect that we have in these articles is the possibility of having groups that can be customized according to the needs of the trainer or the learner, and dynamic groups that change over time due to the mobility of the learners. Two articles Zurita, Nussbaum and Salinas [52], Tan, Kinshuk, Huang [49] propose a method for the dynamic management of learner groups.

\section{Proposal for a training system for a learner's group in a Mobile Learning context}

The MCSL proves to be a practical learning approach for those who wish to improve their knowledge or carry out continuous training. We want to propose a mobile learning system for professionals who have spatio-temporal constraints to carry out their learning. Distance learning is beneficial only when there is real collaboration between learners. Cooperatively alludes to the establishment of a group of learners. How to train these groups is our main concern. Should it be done manually or automatically by the algorithm implementation? But the manual training 
of groups proves to be complex, because many parameters have to be taken into account and the motivation of the learners must be maintained in the learning activities. As seen previously many works, coinciding with advances in mobile technology, propose learner group training approaches in the MCSCL. Through this study of the state of the art, we propose generic learner group formation architecture in the MCSCL (fig. 1).

\begin{tabular}{|l|l|l|l|l|}
\hline \multicolumn{5}{|c|}{ INPUT } \\
\hline $\begin{array}{l}\text { Personal } \\
\text { characteristics }\end{array}$ & \multicolumn{2}{|c|}{ context information } & $\begin{array}{l}\text { Learners' } \\
\text { behaviours }\end{array}$ \\
\hline & $\downarrow$ & \\
\hline \multicolumn{5}{|c|}{ Learning group Algorithm } \\
\hline \multicolumn{5}{|c|}{ OUTPUT } \\
\hline$\downarrow$ & $\downarrow$ & $\downarrow$ & $\begin{array}{l}\text { dynamic } \\
\text { group }\end{array}$ & $\begin{array}{l}\text { Custom } \\
\text { group }\end{array}$ \\
\hline Effective & $\begin{array}{l}\text { Number of } \\
\text { group }\end{array}$ & Super-group & Subgroup \\
\hline
\end{tabular}

Fig. 1. Generic learner group training architecture.

We intend to propose an algorithm for the formation of heterogeneous groups of learners that receive as parameters:

- Personal traits : gender, title (employed, unemployed), work experience, level of domain knowledge (highest diploma);

- Geographical position: we retrieve the geographical coordinates of learners from their mobile device by activating their GPS;

- Social we analyze the rate of interaction of learners in terms of answers given to the questions of other learners.

In output we have:

- The group size we set at five. A small number of learners promote meaningful interactions while facilitating coordination and group management [7] [25] ;

- We choose a hierarchical organization (super-group and subgroup) of groups to facilitate assignment from the learners to the groups ;

- The groups trained are updated periodically to take into account the high mobility of learners who change positions frequently. 


\begin{tabular}{|c|c|c|c|c|c|}
\hline \multicolumn{6}{|c|}{ INPUT } \\
\hline \multicolumn{2}{|c|}{$\begin{array}{l}\text { Gender } \\
\text { Title } \\
\text { experiences } \\
\text { knowledge }\end{array}$} & \multicolumn{2}{|c|}{$\begin{array}{l}\text { Geographical } \\
\text { position }\end{array}$} & \multicolumn{2}{|c|}{ Social interaction } \\
\hline & & $\downarrow$ & & & \\
\hline \multicolumn{6}{|c|}{ Learning group Algorithm } \\
\hline \multicolumn{6}{|c|}{ OUTPUT } \\
\hline \multicolumn{2}{|l|}{$\downarrow$} & $\downarrow$ & $\downarrow$ & \multicolumn{2}{|l|}{$\downarrow$} \\
\hline $\begin{array}{c}\text { Effective } \\
5\end{array}$ & $\begin{array}{l}\text { Number of } \\
\text { group }\end{array}$ & $\begin{array}{l}\text { Super-group } \\
\text { yes }\end{array}$ & $\begin{array}{c}\text { Subgroup } \\
\text { yes }\end{array}$ & $\begin{array}{l}\text { dynamic } \\
\text { group } \\
\text { yes }\end{array}$ & $\begin{array}{l}\text { Custom } \\
\text { group }\end{array}$ \\
\hline
\end{tabular}

Fig. 2. Algorithm for training groups of learners.

\section{1 implementation of the algorithm}

We intend to deploy the solution in Senegal for professionals who wish to improve their skills by performing continuous training [53] [54]. We find that these professionals face many spatio-temporal constraints to attend a face-to-face training.

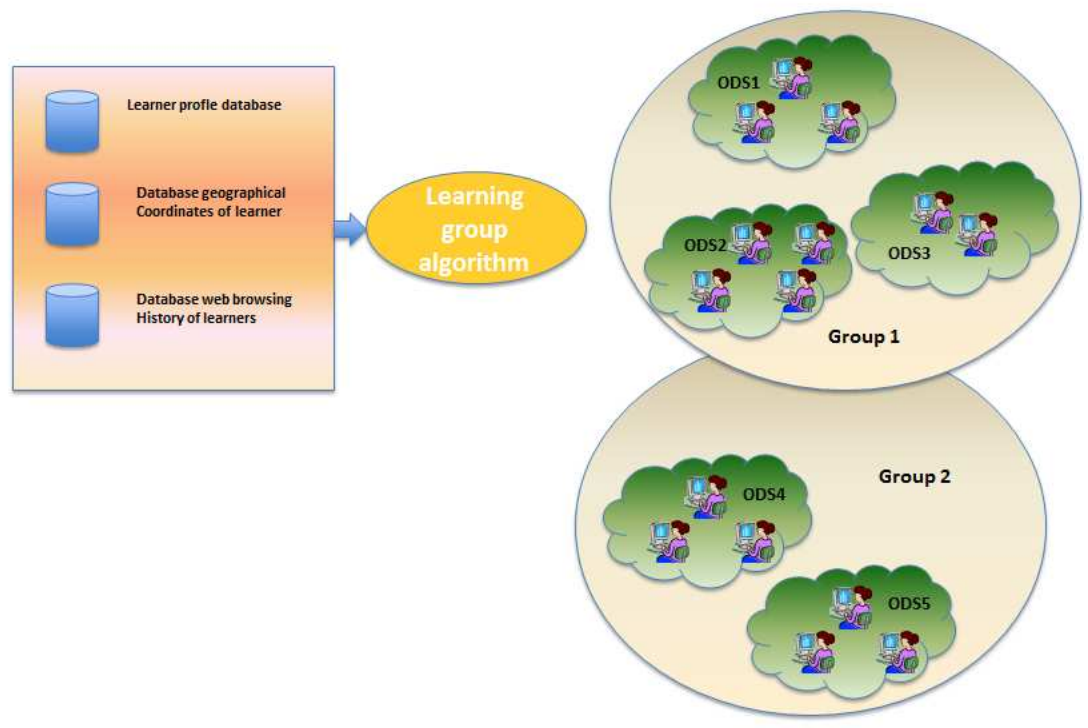

Fig. 3. System of formation of groups of learners.

The learners are grouped in open digital spaces (ODS) according to their geographical position [55], their profile, as well as the browsing history of the web pages. These data are stored in databases and analyzed and exploited to form groups of learners. The principle of the algorithm is to associate the learner with the nearest 
ENO after locating it. For this, our algorithm is based on the Dijkstra algorithm [56] which serves to solve the problem in the shortest path.

\subsection{Principle of group formation}

\section{Method 1}

In this first method, our algorithm is characterized by:

- Groups that are identified by a fixed value and are named ODS ;

- ODSs are organized in ascending order ;

- The search for a current ODs: the dijkstra algorithm is applied to determine the ODS closest to the learner (mobile node) who wants to connect;

- The ODS is uniquely identified by the couple (Latitude, Longitude)

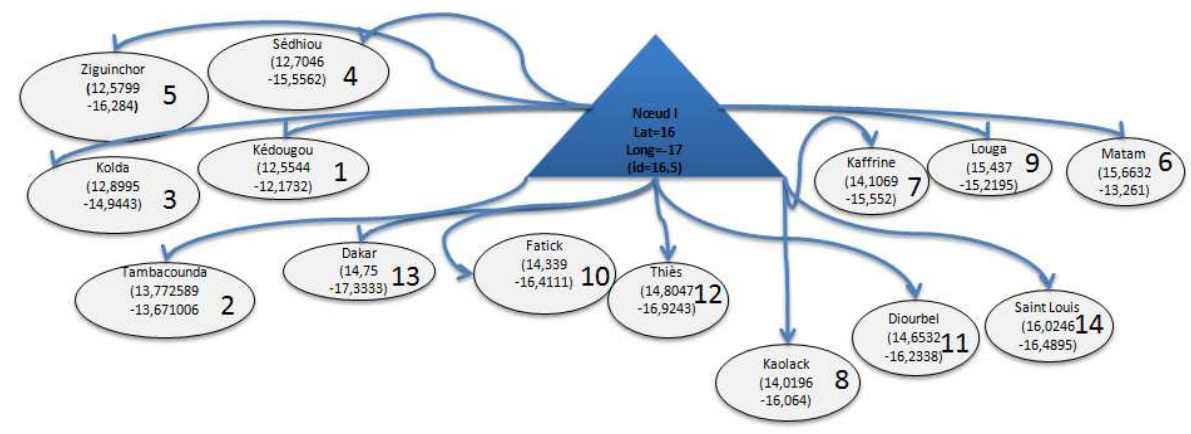

Fig. 4. Search algorithm with method 1.

By applying the principle of djisktra, to search the current ODS of node I, we will browse the nodes step by step starting with the node that has the identifier. Thus our search begins with the node Kédougou and ends with the node Saint Louis which will be the current ODS of the node I.

Doing an analysis of the algorithm, the parameter of complexity is related to the number $\mathrm{n}$ corresponding to the number of ODS. To improve the algorithm it will be necessary to reduce the number of ODSs to be traveled to find a current ODS.

Method 2

In this second method we try to improve the algorithm of the first method, so our second proposed algorithm is characterized by:

- Associate a group number for each ODS;

- Associate with each mobile node (learner) a group number that corresponds to its original group ;

- $\quad$ Regroup the ODSs by group ; 
- Find the current ODS starting from the originating group of the mobile node;

- Each group covers an identifier interval ;

- The maximum number of ODSs in a group is limited to five.

- The groups are as follows :

- $\quad$ Group 0: identifier is between 11 and 11.9

- $\quad$ Group 1: identifier is between 12 and 12.9

- Group 2: identifier is between 13 and 13.9

- $\quad$ Group 3 : identifier is between 14 and 14.9

- $\quad$ Group 4 : identifier is between 15 and 15.9

- $\quad$ Group 5 : identifier is between 16 anf 16.9

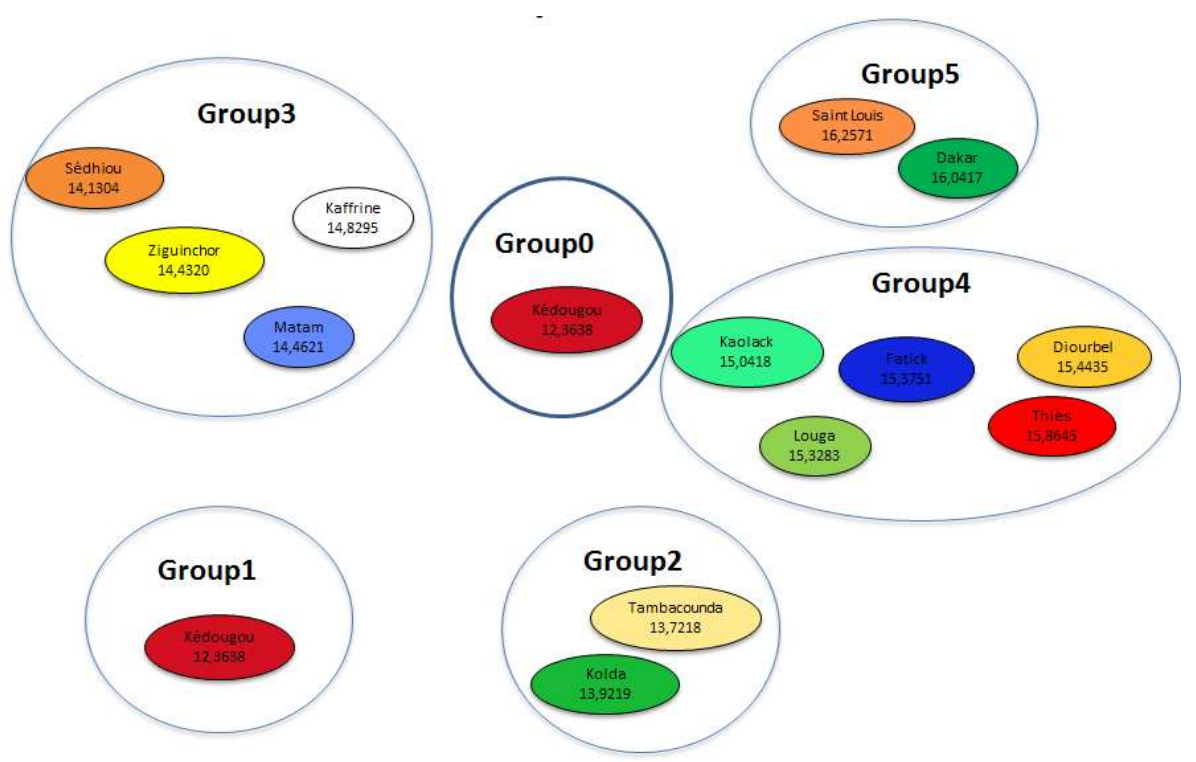

Fig. 5. Grouping of ODSs by group.

By always analyzing this algorithm in relation to the previous one, the complexity is less. Decidedly, the number of ODSs to be covered is reduced since the ODSs are organized in groups. FIG. 6 shows the time taken during the localization of ODS using the two methods presented above: 


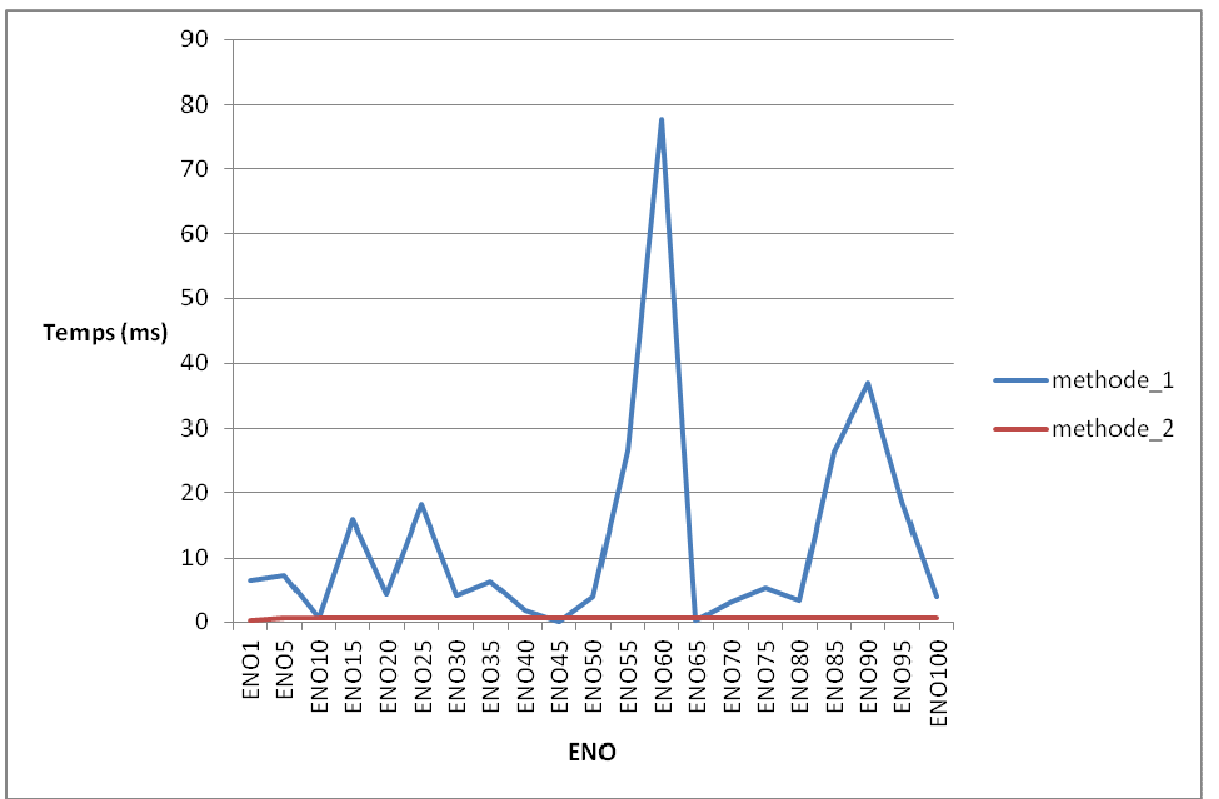

Fig. 6. Comparison of the two methods.

The second method (red curve) with constant complexity is the best approach to implement because we find a real reduction in the search time of the closest ODS according to the parameters defined previously. Indeed, the maximum time observed in the second method is $0.6 \mathrm{~s}$ contrary to method 1 where the maximum observed time reaches $80 \mathrm{~s}$.

\section{Conclusion and Perspectives}

This paper is part of our doctoral research work. The objective of our work is to propose a mobile learning solution to Senegalese professionals who face spatiotemporal constraints to continue their learning by attending classes. Thus we have established a detailed state of the art on the practices of Mobile Learning. One of the major issues in Mobile Learning is to be able to form groups of learners that are sustainable over time while ensuring real collaboration between these learners. This has prompted us to focus our research on the formation of learner groups in Mobile Computer Supported Collaborative Learning (MCSCL). In summary, what we can retain is that to form groups of learners assuring a positive interdependence, the following criteria must be taken into account: Personal traits; Geographic position; Social interactions.

The algorithm that we have proposed can be adapted to any mobile learning situation. As a perspective, we plan to deploy the solution and then evaluate its impact in the learning process of Senegalese professionals. 


\section{References}

1. P. C. Abrami, L'apprentissage coopératif:Théories,méthodes et activités, 1995.

2. D. W. Johnson, R. T. Johnson et E. J. Holubec, Cooperation in the Classroom Revised edition, 2008.

3. 3. S. Caballé, F. Xhafa et L. Barolli, «Using mobile devices to support online collaborative learning».

4. 4. E. R. Slavin, Cooperative Learning: Theory, Research and Practice, 2nd Edition, Boston: Allyn \& Bacon, 1995.

5. 5. C. J. Roseth, D. W. Johnson et R. T. Johnson, «Promoting early adolescents achievement and peer relationships: The effects of cooperative,competitive, and individualistic goal structures,» Psychological Bulletin, vol. 134, ${ }^{\circ} \% 12$, pp. 223246, 2008.

6. 6. D. W. Johnson et R. T. Johnson, Cooperation and Competition, 1989.

7. 7. D. W. Johnson et R. Johnson, «An Educational Psychology Success Story: Social Interdependance Theory and Cooperative Learning,» EDUCATIONAL RESEARCHER, vol. 38, n \% \% 15, pp. 365-379, 2009.

8. 8. M. Windschitl, «Using Small-Group Discussions in Science Lectures: A study of Two Professors,» College Teaching, vol. 47, n \%11, pp. 23-27, 1999.

9. 9. R. E. Slavin, E. A. Hurley et A. Chamberlain, Cooperative Learning and Achievement: Theory and Research, 2003.

10. 10. D. W. Johnson, R. T. Johnson et K. Smith, «The State of Cooperative Learning in Postsecondary and Professionnal Settings,» Educational Psychology Review, vol. 19, $\mathrm{n}^{\circ} \% 11$, pp. 15-29, 2007.

11. 11. H. Shachar et S. Fischer, «Cooperative learning and the achievement of motivation and perceptions of students in 11th grade chemistry classes,» Learning and instruction, vol. 14, $\mathrm{n}^{\circ} \% 11$, pp. 69-87, 2004.

12. 12. D. W. Johnson, R. T. Johnson et B. Taylor, «Impact of cooperative and individualistic learning onhigh-ability students' achievement, self-esteem, and social acceptance,» Journal of Social Psychology, vol. 133, n \%16, pp. 839-844, 1993.

13. 13. J. Nichols et R. Miller, «Cooperative learning and student motivation,» Comtemporary Educational Psychology, vol. 19, n%12, pp. 167-178, 1994.

14. 14. K. J. Topping, A. Thurston, A. Tolmie, D. Christie, P. Murray et E. Karagiannidou, «Cooperative learning in science: Intervention in the secondary school,» Research in Science \& Technological Education, vol. 29, n%11, pp. 91106, 2011.

15. 15. A. Bandura, «A social cognitive theory of personality,» Handbook of personality, pp. 154-196, 1999.

16. 16. Y. K. Law, «The effects of cooperative learning on enhancing Hong Kong fifth graders' achievement goals, autonomous motivation and reading proficiency,» Journal of Research in Reading, vol. 34, $\mathrm{n}^{\circ} \% 14$, pp. 402-425, 2011.

17. 17. A. J. Elliot, «A conceptuel history of the achievement goal construct,» Handbook of competence and motivation, pp. 52-72, 2005.

18. 18. A. Bertucci, S. Conte et D. W. Johnson, «The impact of size of cooperative group on achievement,social support,and self-esteem,» The journal of General Psychology, vol. 137, n० \%13, pp. 256-272, 2010.

19. 19. E. S. Chapman et M. T. Cope, «Group reward contingencies and cooperative learning: immediate and delayed effects on academic performance,self esteem, and sociometric ratings,» Social Psychology of Education, vol. 7, n $\% 11$, pp. 73-87, 2004.

20. 20. R. E. Slavin, C. Lake, S. Davis et N. Madden, «Effective programs for struggling 
readers: A best-evidence synthesis,» Educational Research Review, vol. 6, n \%11, pp. 1-26, 2011.

21. 21. T. J. Berndt et K. Keefe, «Friends' influence on adolescents' adjustement to school,» Child Development, vol. 66, $\mathrm{n}^{\circ} \% 15$, pp. 1312-1329, 1995

22. 22. D. Buhrmester, «Intimacy of friendship,interpersonal competence, and adjustment during preadolescence and adolescence,»Child Development, vol. 61, n%14, pp. 101-1111, 1990.

23. 23. K. R. Wentzel, C. M. Barry et K. Caldwell, «Friendships in middle school: influences on motivation and scholl adjustment,» Journal of Educational, vol. 96, n $\% 12$, pp. 195-203, 2004.

24. 24. S. George, Apprentissage collectif à distance. SPLACH: un environnement informatique support d'une pédagogie de projet, Maine, 2001.

25. 25. R. M. Gillies, «The effects of cooperative learning on junior high school students during small group learning,» Learning and Instruction, vol. 14, $\mathrm{n}^{\circ} \% 12$, pp. 197213, 2004

26. 26. J. Ballantine et $\mathrm{P}$. MvCourt Larres, «Cooperative Learning: A pedagogy to improve students' generic skills,» Education + Training, vol. 49, n%12, pp. 126137, 2007.

27. 27. M. Lejk, M. Wyvill et S. Farrow, «Group assessment in sytems analysis and design: A comparison of the performance of streamed and mixed ability groups,» Assessment and Evaluation in Higher Education, vol. 24, $\mathrm{n}^{\circ} \% 11$, pp. 5-14, 1999.

28. 28. Y. Rouiller et J. Howden, La pédagogie coopérative : Reflets de pratiques et approfondissements, 2009.

29. 29. R. F. Stein et S. Hurd, «Using student teams in the classroom: a faculty guide».

30. 30. S. Graf et R. Bekele, «Forming heteregeneous groups for intelligent collaborative learning systems with ant colony optimization,» chez Proceedings of the 8th international conference on intelligent tutoring systems: lecture notes in computer science, Jhongli, Taiwan, 2006.

31. 31. K. Zhang, L. Cui, H. Wang et Q. Sui, «An improvement of matrix-based clustering method for grouping learners in e-learning,» chez Proceedings of the 11th international conference on computer supported cooperative work in design, Melbourne,Australia, 2007.

32. 32. Y. A. Pollalis et G. Mavrommatis, «Using similarity measures for collaborating groups formation: a model for distance learning environments,» European journal of operational research, vol. 193, $\mathrm{n}^{\circ} \% 12$, pp. 626-636, 2009.

33. 33. M. Cocea et G. D. Magoulas, «Group formation for collaboration in exploratory learning using group technology techniques,» chez Proceedings of the 14th international conferenceon knwoledge-based and intelligent information and engineering systems, lecture notes in computer science, Cardiff, 2010.

34. 34. Y. T. Lin, Y. H. Huang et S. C. Cheng, «An automatic group composition system for composing collaborative learning group using enhanced particle swarm optimization,» Computers \& Education, vol. 55, n \%14, pp. 1483-1493, 2010.

35. 35. H. Sadeghi et A. Kardan, «Toward effective group formation in computersupported collaborative learning,» Interactive Learning Environments, vol. 24, $\mathrm{n}^{\circ} \% 13$, pp. 382-395, 2016.

36. 36. D. Jin, Z. Qinghua, D. Jiao et G. Zhiyong, «A method for learner grouping based on personality clustering,» chez proceedings of the 10th international conference on computer supported cooperative work in design, Nanjing, 2006.

37. 37. A. Gogoulou, E. Gouli, G. Boas, E. Liakou et M. Grigoriadou, «Forming homogeneous, heteregeneous and mixed groups of learner,» chez Proceeding of workshop on personalization in learning environments at individual and group level in conjunction with the 11th international conference on user modeling, 
Corfu,Greece, 2007.

38. 38. S. L. Tanimoto, «The squeaky wheel algorithm: automatic grouping of students for collaborative projects,» chez Proceeding of workshop on personalization in learning environments at individual and group level in conjunction with the 11th international conference on user modeling, 2007.

39. 39. D. Zakrzzewska, «Cluster analysis in personalized e-learning systems,» Intelligent systems for knowledge management, studies i computational intelligence, vol. 252, pp. 229-250, 2009.

40. 40. A. Ounnas, H. Davis et D. Millard, «A framework for semantic group formation in education,» Educational Technology and Society, vol. 12, n%14, pp. 43-55, 2009.

41. 41. Z. C. Ani, A. Yasin, M. Z. Husin et Z. A. Hamid, «A method for group formation using genetic algorithm,» International Journalon Computer Science and Engineering, vol. 2, $\mathrm{n}^{\circ} \% 19$, pp. 3060-3064, 2010.

42. 42. R. Hubsher, «Assigning students to groups using general and context-specific criteria,» IEEE Transactions on learning technologies, vol. 3, n \%13, pp. 178-189, 2010.

43. 43. V. Yannibelli et A. Amandi, «A deterministic crowding evolutionary algorithm to form learning teams in a collaborative learning context,» Expert Systems with Applications, vol. 39, $\mathrm{n}^{\circ} \% 110$, pp. 8584-8592, 2012.

44. 44. J. Moreno, D. A. Ovalle et R. M. Vicari, «A genetic algorithm approach for group formation in collaborative learning considering multiple student characteristics,» Computers \& Education, vol. 58, n \% 11, pp. 560-569, 2012.

45. 45. L. K. Soh, N. Khandaker et H. Jiang, «Multiagent coalition formation for computer-supported cooperative learning,» chez Proceedings of the 5th international joint conference on autonomous agents and multiagent systems, New York, 2006.

46. 46. S. Amara, J. Macedo, F. Bendella et A. Santos, «Group Formation in Mobile Computer Supported Collaborative Learning Contexts: A systematic literature review,» Journal of Educational Technology \& Society, vol. 19, pp. 258-273, 2016.

47. 47. R. Messeguer, E. Medina, D. Royo, L. Navarro et J. P. Juarez, «Group prediction in collaborative learning,» chez The 6th IEEE International Conference on Intelligent Environments, 2010.

48. 48. M. El-Bistoury, H. Ogata, S. Rahman et Y. Yano, «Social knowledge awareness map for computer supported ubiquitous learning environment,» Educational Technology \& Society, vol. 13, n ${ }^{\circ} \% 14$, pp. 27-37, 2010.

49. 49. Q. Tan, Kinshuk, Y. L. Jeng et Y. M. Huang, «A collaborative mobile virtual campus system based on location-based dynamic grouping,» chez Proceedinf of the 10th IEEE international conferenceon advanced learning technologies, Los Alamitos, 2010.

50. 50. A. Mujkanovic, D. Lowe et K. Willey, «Adaptative group formation to promote desired behaviours,» chez Profession of Engineering Education: Advancing Teaching,Research and Careers: 23rd Annual Conference of the Autralian Assoication for Engineering Education, Melbourne, Australia, 2012.

51. 51. C. Yin, Y. Dong, Y. Tabata et H. Ogata, «Recommendation of helpers based on personal connections in mobile learning,» chez Seventh IEEE International Conference on Wireless, Mobile and Ubiquitous Technology in Education, Los Alamitos, 2012.

52. 52. G. Zurita, M. Nussbaum et R. Salinas, «Dynamic grouping in collaborative learning supported by wireless handhelds,» Educational Technology \& Society, vol. 8, n $\% 13$, pp. 149-161, 2005.

53. 53. M. H. Mballo, R. Hotte, A. Diop et I. Niang, «Mobile Learning, a Solution to Vocational Training in Senegal,» chez in International Conference on Web \& Open 
Access to Learning, Dubai (United Arab Emirates), 2014.

54. 54. M. H. Mballo, A. Diop, R. Hotte et I. Niang, «A model of Computer Support to Mobile Learning in Senegalese Educational System,» chez Global Summit on Computer Information Technology-International Conference on Education \& eLearning Innovation ICEELI'15, 2015.

55. 55. M. H. Mballo, A. Diop, R. Hotte et I. Niang, «Mobile Learning: hierarchical architecture,» chez Word Symposium on Computer apllication \& research WSCAR'16, Egypte, 2016.

56. 56. Wikipedia, «Algorithme de Dijkstra,» 2016. [En ligne]. Available: https://fr.wikipedia.org/wiki/Algorithme_de_Dijkstra. [Accès le 2016].

57. 57. Y. M. Huang et T. T. Wu, «A systematic approach for learner group composition utilizing U-learning portfolio,» Educational Technology \& Society, vol. 14, $\mathrm{n}^{\circ} \% 13$, pp. 102-117, 2011.

58. 58. J. J. Huang, S. J. Yang, Y. M. Huang et I. Y. T. Hsiao, «Social learning networks: build mobile learning networks based on collaborative services,» Educational Technology \& Society, vol. 13, ${ }^{\circ} \% 13$, pp. 78-92, 2010.

59. 59. J. C. Hsieh, C. Chen et H. F. Lin, «Social interaction mining based on wireless sensor networks for promoting cooperative learning performance in classroom learning environment,» chez The 6th IEEE interantional conference on wireless, mobile, and ubiquitous technologies in education, Los Alamitos, 2010.

60. 60. A. Giemza, S. Manske et H. U. Hoppe, «Siupporting the formation of informal learning groups in a heteregenous information environment,» chez Proceeding of the 21 st intenational conference on computers in Education, Bali, Indonesia, 2013.

61. F. Yang, M. Wang, R. Shen et P. Han, «Community-organizing agent: An artificial intelligent system for building learning communities among large numbers of learners,» Computers \& Education, vol. 49, n \% 12, pp. 131-147, 2007.

62. 62. M. Muehlenbrock, «Formation of learning groups by using learner profiles and context information,» chez Proceedings of the 2005 conference on Artificial Intelligence in Education:Supporting Learning through Intelligent and Socially Informed Technology, Amsterdam, 2005. 